\title{
El Control de la Inflación en Gobiernos Progresistas: Rescatar a Juan Noyola Vásquez por el Fin de la Concepción Monetarista
}

\author{
Monika Meireles ${ }^{(*)}$ \\ Fernando Correa Prado(*)
}

\begin{abstract}
Resumen: América Latina ha vivido en los últimos diez años cambios sociales importantes, revelados al contrastar las plataformas políticas actuales con las vigentes en las décadas de 1980 y 1990. En el ámbito de la política monetaria, empero, parece haber una continuidad de la perspectiva monetarista centrada en la estabilización de la moneda y el control de la inflación. Como intento de hacer frente al estancamiento relativo del pensamiento social latinoamericano contemporáneo acerca de los orígenes de la inflación y las formas de encararla, el presente trabajo se propone a revisar el aporte de la concepción estructuralista y su entendimiento de la tendencia al aumento del nivel general de precios que acomete la región, considerando especialmente la contribución del economista mexicano Juan Noyola Vásquez.
\end{abstract}

Palabras clave: Inflación, Estructuralismo Latino-Americano, Juan Noyola Vásquez.

Abstract: Latin America has witnessed over the last ten years major social changes, revealed by contrasting the current political platforms with those adopted in the 1980 s and 1990s. In the area of monetary policy, however, seems to have a continuity of the monetarist view focuses on stabilizing the currency and controlling inflation. As an attempt to cope with the relative stagnation of contemporary Latin American social thought about the origins of inflation and ways to address it, this article main goal is to pass on review the theoretical contribution made by the structuralist tradition on the origins and causes of the systematic inflationary process that harass the region, reflected on the work of the Mexican economist, Juan Noyola Vásquez.

Keywords: Inflation, Latin American Structuralism, Juan Noyola Vásquez.

(*) Licenciada en economía por la Faculdade de Ciências Econômicas de la Universidade de São Paulo (USP), con maestría en Integração de América Latina por el Programa de Pós-graduação em Integração de América Latina (PROLAM) de la misma institución y doctorante en el Programa de Posgrado de Estudios Latinoamericanos de la Universidad Nacional Autónoma de México (UNAM).E-mail: meireles@usp.br.

(**) Licenciado en economía por el Departamento de Ciencias Econômicas de la Universidade Federal de Santa Catarina (UFSC); en proceso de defensa de Tesis de Maestría en el Posgrado de Estudios Latinoamericanos de la Universidad Nacional Autónoma de México (UNAM). Actualmente trabaja como investigador en el Instituto de Estudios Latinoamericanos de la UFSC, en un convenio con el Instituto de Pesquisa Econômica Aplicada (IPEA). E-mail: fernandoprado@gmail.com. Recebido em: 21.2.2010 e aceito em: 19.3.2010. 


\section{INTRODUCCIÓN}

América Latina ya empezó a hacer su balance de lo que fue la era neoliberal en la región. Quizás la evidencia inicial de tal proceso se revele a través de los recientes ejercicios electorales, en los cuales varios países optaran por jefes del ejecutivo con plataformas de gobierno marcadamente distintas de aquellas que imperaron en los ochenta y noventa ${ }^{(1)}$. Ahora bien, pasada casi una década del inicio de este proceso, la reflexión crítica acerca de estas experiencias se hace necesaria. En este sentido, uno de los puntos que se destacan es la manutención de una política monetaria de corte neoclásico-monetarista centrada en la estabilización de la moneda y control de la inflación.

Pese el cambio significativo en la composición y volumen del gasto público - que pasó a privilegiar el "gasto social” — hasta el momento, y en líneas generales, los gobiernos de América Latina optaron por el mantenimiento de una gestión monetaria estrictamente ortodoxa y conservadora, que preserva la pauta neoliberal en relación al entendimiento y control de la inflación. Esta postura, a su vez, puede ser percibida simultáneamente como causa y consecuencia de la inexistencia actual de un pensamiento contra-hegemónico acerca del papel de la moneda en el sistema mundial capitalista.

Admitiendo como hipótesis — quizás ingenua y demasiada generosa con la composición elitista que parece se configurar en varios de los actuales gobiernos latinoamericanos — que tal "deslice" en el manejo monetario se debe al estancamiento relativo en el pensamiento social latinoamericano contemporáneo en el sentido de formular una teoría alternativa sobre los orígenes del proceso inflacionario y las diferentes formas de encarar este fenómeno, el presente trabajo se propone a revisar el aporte de la concepción estructuralista y su entendimiento de la tendencia al aumento del nivel general de precios. Más precisamente, se busca dar elementos para reinterpretar, a la luz del rescate de la contribución pionera del economista mexicano Juan Noyola Vázquez, la constante presión inflacionaria subyacente a todas las etapas y configuraciones del llamado desarrollo latinoamericano. Frente al desconocimiento de la vida y obra de Noyola, vale la pena exponer algunos de sus antecedentes biográficos, lo que será realizado en el apartado que sigue esta introducción.

En la segunda sección se hará el rescate de una contribución particular de Noyola acerca de las causas estructurales y de los mecanismos de propagación de la inflación. Como se verá, en su propuesta se encuentran las bases de lo que vino a ser una explicación histórico-estructural de la inflación — y, además, se encuentran elementos para una posible concepción latinoamericanista de la moneda.

Al final del trabajo, más que apuntar a conclusiones definitivas - lo que en sí mismo es contraproducente en un trabajo del género — la intención será la de revelar los límites

(1) Entre los hechos que se contabilizan, en ese giro, en el escenario político latinoamericano, se destacan: las sucesivas elecciones de Hugo Chávez Frías en Venezuela desde 1998; la victoria en Brasil de Lula da Silva en 2002 y su posterior reelección; la llegada de Néstor Kirchner a la Casa Rosada en 2003 y la victoria de Cristina Fernández, su sucesora en el cargo; el triunfo electoral del Frente Amplio, representado por Tabaré Vázquez en Uruguay en 2004; la ascensión de Evo Morales a la presidencia de Bolivia en 2005; la presidencia chilena asumida por Michelle Bachelet en 2006; y, en el mismo año, las conquistas de Rafael Correa en Ecuador y de Daniel Ortega en Nicaragua; y, más recientemente, el éxito electoral y el inicio del mandato de Fernando Lugo en Paraguay y de Mauricio Funes en El Salvador. 
de la actual política monetaria caso ésta no supere las interpretaciones impuestas por la cartilla neoliberal. Con ello, se posibilitará al menos (re)abrir el debate en torno a la inflación y, sobre todo, acerca del papel de la moneda en clave latinoamericanista.

\section{ANTECEDENTES BIOGRÁfICOS: PERIPECIAS DE UN INTRÉPIDO ECONOMISTA}

Aunque haya sido prematuramente abreviada - un accidente aéreo le quitó la vida cuando contaba con apenas 40 años ${ }^{(2)}$ — la aguda contribución teórica y la enseñanza de la estrecha articulación entre la teoría y la práctica política llevadas a cabo por Juan Noyola Vásquez representan inconmensurable aprendizaje para las nuevas generaciones de científicos sociales latinoamericanos.

Ese breve repaso de los hechos biográficos más representativos de la vida de Juan Noyola Vázquez no cumple una mera función protocolar o de "ambientación” del autor analizado, una vez que revela como su trayectoria profesional marcó definitivamente sus acepciones teóricas y prácticas políticas. Así, Noyola como egresado de la UNAM, como servidor del Fondo Monetario Internacional - FMI, como funcionario de la Comisión Económica para la América Latina y el Caribe - CEPAL y, finalmente, como dirigente revolucionario en Cuba, representa etapas de la madurez del pensamiento y del creciente compromiso con el proyecto de construcción de una sociedad en la que primara la justicia social.

\section{De San Luis Potosí a la CEPAL}

Nacido en la ciudad de San Luis Potosí, en 1922, tempranamente Juan Noyola Vásquez migró junto con su familia a la capital del país. Como tantos otros pensadores y artistas mexicanos, él "se formó como hombre y como intelectual dónde pudo, es decir en la Ciudad de México, no obstante haber nacido provinciano” (ESCAMILLA; MANRIQUE, 1991, p. 26) $)^{(3)}$. Allí frecuentó a colegios de renombre y, subsecuentemente, estudió de manera

(2) Murieron también en el avión que estrelló cerca de Lima en 27 de noviembre de 1962, al regresar a Cuba tras la VII Conferencia de Regional de la Organización de la Naciones Unidas para la Agricultura y Alimentación en América Latina (FAO) realizada en Rio de Janeiro, los siguientes integrantes de la delegación cubana: Raúl Cepero Bonilla, economista e historiador cubano que había desempeñado como Ministro de Comercio (1959-1960) y como presidente del Banco Nacional de Cuba, cargo que ejercía de 1960 hasta ese entonces; Sergio Restano Castro, Andrés González Hernández, Armando Valdés Quesada, José Aníbal Maestri Tizón, Rodrigo Cabello Volosky, Álvaro Barba Machado, Gilberto León Alfonso y Eladio Hernández León. Tras el accidente, en el 4 de diciembre del mismo año, le fue otorgada por el gobierno cubano a Juan Noyola la ciudadanía cubana sin prejuicio de su nacionalidad mexicana. En el Acta del Consejo de Ministros — cuya reproducción puede ser encontrada en la introducción hecha por Jesús Silva Herzog al libro de Noyola Vásquez (1978) — se le dedica tal otorgamiento "en atención a que en él concurrían las condiciones excepcionales que dicho precepto demanda, dado su demostrado amor por Cuba, su identificación con la Revolución Cubana y su decidida actitud anti-imperialista”. Otra serie de homenajes le fueron rendidas en Cuba, bien como en su México natal. En el campo de la investigación científica, el 27 de noviembre de cada ano también es la fecha en que se da a conocer el ganador del Premio Juan F. Noyola Vázquez de la Revista Investigación Económica, de la UNAM, por el mejor artículo académico allí publicado.

(3) En el primer capítulo de esa publicación se encuentra una interesante reflexión acerca de las condicionantes del contexto histórico mexicano en la conformación intelectual de Noyola Vásquez. En la publicación también se encuentra agrupada una útil recopilación de sus principales ensayos, artículos, informes técnicos y conferencias. 
simultánea las carreras de Sociología, en el Centro de Estudios Sociales del Colegio de México, y de licenciatura en Economía, en la UNAM. Bajo la invitación del profesor Jesús Silva Herzog, ya en los años cuarenta, Noyola pasó a colaborar en el Comité de Aforos y Subsidios al Comercio Exterior, que aquél presidia. En 1946, a los 24 años, se traslada a Washington para prestar sus servicios en la División Latinoamericana del FMI. En el FMI, Noyola tuvo como jefe inmediato al cubano Felipe Pazos ${ }^{(4)}$, a quien consideró "uno de los economistas latinoamericanos más destacados y maestro de toda una generación de economistas latinoamericanos" (NOYOLA, 1978, p. 25). Ya de regreso a México, trabajó en su tesis de licenciatura y la defendió en 1949. Herzog fue el profesor que presidio el jurado que aprobó su examen profesional ${ }^{(5)}$.

Su ingreso a la CEPAL, en el año de 1950, coincidió con la incorporación al organismo de otros talentosos economistas latinoamericanos. Bajo la dirección de Raúl Prebisch, se concentraron allí, durante los años cincuenta, intelectuales como Celso Furtado, José Medina Echavarría, Regino Botti, Jorge Ahumada, Aníbal Pinto y Osvaldo Sunkel. Bielschowsky (1998a, p. 18) resume lo que es consensual a varios estudiosos del estructuralismo latinoamericano: "los años cincuenta para la CEPAL fueron los del el auge de la creatividad y de la capacidad de osar y influenciar”. En ese ambiente propicio a la reflexión creativa acerca del desarrollo y de las causas del subdesarrollo latinoamericano, Noyola encontró estímulo junto a interlocutores que compartían su postura no alineada con los preceptos de la ortodoxia en las ciencias económicas. Los primeros trabajos realizados por Noyola en la CEPAL versaron sobre el desarrollo en Chile y El Salvador ${ }^{(6)}$. Tras algunos años de servicios en la sede en Santiago de Chile, él se traslada para la subsede de la CEPAL para México y Caribe, en la Ciudad de México. Allí trabajó conjuntamente con Celso Furtado, bajo la dirección de Víctor Urquidi, en un polémico estudio sobre el sector externo y la economía mexicana. Escasas son las referencias a ese documento; de hecho, su circulación

(4) Felipe Pazos fue un importante y polémico economista cubano de filiación desarrollista-cepalina. Entre sus atribuciones se destacan haber sido uno de los miembros de la delegación cubana en Bretton Woods, la nombrada jefatura de la División Latinoamericana del FMI, y también ser el presidente que precedió a Ernesto Che Guevara en el Banco Nacional de Cuba, del cual se alejó por desacuerdos con el gobierno revolucionario, y pasa a asumir una serie de puestos y funciones en organismos multilaterales. Para una revisión de corrientes y tradiciones del pensamiento económico cubano, véase Ortega; Laffita; Molina (2000).

(5) La tesis nombrada “Desequilibrio fundamental y fomento económico en México" fue considerada por Herzog como "brillante", justificando su aprobación por unanimidad, con mención honorífica tanto de la tesis cuanto de la réplica.

(6) El trabajo sobre El Salvador es de autoría colectiva y se publica firmado por la CEPAL como: "El desarrollo económico de El Salvador” en 1959 (E/CN.12/495/Rev. 1 México). El trabajo sobre Chile lleva la firma individual de Noyola y se nombra "Inflación y desarrollo económico en Chile: un borrador", de 1955. Primeramente, se restringe a circulación y debates en el interior de la CEPAL. Posteriormente, ese estudio se expande y se da a conocer con más notoriedad en una conferencia que profiere en la UNAM, en 1956, titulada "El desarrollo económico y la inflación en México y otros países latinoamericanos”. Una transcripción de la conferencia fue publicada en la revista Investigación económica, XVI, n. 4, México, 1956 - posteriormente se publicó la integra del debate entre diversos profesores allí presentes y el autor (NOYOLA, 1987). Finalmente, la conferencia toma forma acabada como texto bajo el título Inflación y desarrollo económico en Chile y México, publicada en la revista Panorama económico, año 11, n. 170, Santiago de Chile, 1957. Ese texto también se encuentra reproducido en la edición conmemorativa de 50 años de la CEPAL (BIELSCHOWSKY, 1998b). Las citas al texto mencionado provienen de esta edición - por ser sin duda la más accesible entre aquellas aquí nombradas — y serán indicadas a seguir solamente con el número de la página entre paréntesis. 
quedó restringida al foro interno de debates, siendo incluso su publicación “vetada” por el gobierno mexicano $^{(7)}$.

Su designación como jefe del la misión de la CEPAL/DOAT en Cuba, en 1959, lo puso en contacto directo con los revolucionarios cubanos que en el comando del Estado debatían - y ejecutaban - los cambios esenciales de las estructuras del país. Noyola aceptó tal designación con marcado entusiasmo, una vez que se abría la posibilidad de intervenir de manera bastante cercana - la cercanía que le era permitida como asesor de un organismo multilateral — en los rumbos del desarrollo de un país de la región. En las palabras del propio Noyola:

He creído que la reforma agraria, la industrialización, la mejor distribución del ingreso nacional, el desarrollo económico planificado y el aumento del comercio de los países latinoamericanos entre sí y con el resto del mundo eran los instrumentos más adecuados y más eficaces para elevar el nivel de vida de nuestros pueblos y dirigirse hacia el logro de la justicia social. Por eso consideré siempre que el lugar más adecuado para un economista que creyera en estos principios y que estuviera dispuesto a servirlos era un organismo como la CEPAL que postulaba - la mayor parte de ellos cuando menos - como normas fundamentales de su trabajo de investigación y de asistencia técnica. Con ese espíritu contribuía a los estudios sobre análisis y programación del desarrollo económico de diversos países de América Latina. Nunca pensé, sin embargo, que esos estudios tuviesen un valor puramente académico. Estuve seguro siempre de que llegaría el momento en que se podrían llevar a la práctica los métodos preconizados en estos estudios. Por eso consideré mi designación como jefe de la misión CEPAL/DOAT en Cuba como la tarea más importante que se me hubiera encomendado en mi carrera. [...] Había un motivo más profundo: la Revolución cubana. Por primera vez en la historia de la América Latina se encontraban las condiciones para una transformación profunda justa y racional de la economía y de la sociedad (NOYOLA, 1978, p. 11, cursivas nuestras).

\section{Un hombre en Revolución: Cuba}

En 1960, el sueco Dag Hammarskjöld, entonces secretario general de Naciones Unidas, decidió unilateralmente finalizar la misión cepalina en Cuba, tras 17 meses de su implementación. Esa medida fue decisiva para que Noyola se desligara definitivamente de la CEPAL después de una década de servicios prestados. Evidentemente, la cercanía entre funcionarios del organismo y el proceso revolucionario cubano se tornaron intolerables dentro de lo que representan las Naciones Unidas en el escenario de las relaciones políticas globales. Noyola así lo verbalizó:

“Todo lo que he hecho y lo que he dicho ha estado regido por el espirito de servir a los pueblos de la América Latina en su lucha por alcanzar su bienestar material y

(7) El texto mencionado es El desequilibrio externo en el desarrollo económico latinoamericano: el caso de México. En: La clasificación de la Naciones Unidas recibe el E/CN n. 12/428, México, abr. 1957. El propio Celso Furtado lo definiría como "una rareza para coleccionistas de obras de la CEPAL" (citado en MALLORQUín, 1998, p. 150). 
espiritual. Desde ese punto de vista creo que he cumplido con mi obligación como funcionario de las Naciones Unidas. Sí en algún momento han surgido divergencias o incompa-tibilidades entre la interpretación que yo doy a mi tarea y la que se la dé en otros círculos, lo lamento, no por mí, sino porque ello revela la incomprensión de lo que es la Revolución cubana y revela también que los intereses que se mueven contra ella influyen en el seno de la secretaria de las Naciones Unidas” (1978, p. 11).

Felizmente, Noyola optó por solidificar su compromiso con la Revolución Cubana y con lo que ella inauguraba para el subcontinente. No obedeció al orden de regresar a Santiago de Chile, no quiso volver al conforto de los alfombrados salones de la sede de la CEPAL, abdicó de la estabilidad y seguridad que ofrece el servicio público internacional en nombre de algo que escasea en sus colegas de profesión: convicción personal e intelectual en un proyecto de sociedad sustancialmente distinta. No faltan interpretaciones que adjudican a la decisión tomada por Noyola de quedarse en Cuba un supuesto estancamiento en la originalidad, creatividad, osadía y, consecuentemente, relevancia de sus aportaciones subsecuentes. Sin embargo, consideramos que, además de una decisión que ejemplifica lo que es la coherencia entre teoría y praxis, su producción teórica no decayó en calidad interpretativa, no dejó de ofrecer ingeniosas categorías para nuevos problemas que el cotidiano de la gestión de un gobierno revolucionario demandaba. Sus análisis acerca de la formación estructural cubana, sus estudios sobre planeación económica y su obsesiva insistencia con la formación y capacitación de nuevos cuadros así lo demostran. La nostalgia de escritos sobre la inflación y la moneda por parte del autor que nunca fueron escritos deben ser más bien computadas en la cuenta de la fatalidad de su muerte prematura, en lugar de ser imputada a su convicción en la Revolución que apoyaba.

\section{Noyola: CAUSAS ESTRUCTURALES Y MECANISMOS DE PROPAGACIÓN DE LA INFLACIÓN}

No cabe duda que el análisis estructuralista acerca de la inflación no se resume a un texto y ni siquiera a un autor. En realidad, aún si se limita la mirada a las tres primeras décadas de funcionamiento de la CEPAL, es posible percibir que el tema fue objeto de diversos estudios, y es sólo a partir de la contemplación representativa de los escritos que se puede generar un satisfactorio cuerpo interpretativo de la concepción estructuralista sobre la inflación ${ }^{(8)}$. No obstante todo ello, también es cierto que el documento inicial que abrió las discusiones cepalinas acerca de la inflación fue la conferencia dictada por Noyola en 1956 en la Facultad de Economía de la UNAM, titulada "El desarrollo económico y la inflación en México y otros países latinoamericanos”(9).

En esta conferencia, tras advertir que no habla en nombre de la CEPAL, sino que expone sus puntos de vista personales, Noyola se deslinda claramente de la perspectiva

(8) Entre los autores que trabajaron el tema a partir del enfoque estructuralista, cabe mencionar por lo menos a Osvaldo Sunkel (1958a; 1958b) y Aníbal Pinto (1961; 1973); en el capítulo XII de su libro La economía latinoamericana. Formación histórica y problemas contemporáneos, Celso Furtado (1976, p. 151) cita detalladamente todas las contribuciones para la teoría estructuralista de la inflación.

(9) Ver nota 6. 
monetarista de la inflación y, con eso, sienta las bases de lo que vendría a ser el enfoque estructuralista de la inflación:

"La inflación no es un fenómeno monetario; es el resultado de desequilibrios de carácter real que se manifiesta en forma de aumento del nivel general de precios. Este carácter real del proceso inflacionario es mucho más perceptible en los países subdesarrollados que en los países industriales" (p. 67).

A partir de esta afirmación, el discurso considera rápidamente los esquemas teóricos keynesianos y de la escuela sueca, para luego recordar a Kalecki y, sobretodo, a Henri Aujac, de quien Noyola toma la clara noción de que "la inflación no es sino un aspecto del fenómeno mucho más general de la lucha de clases” (Ibidem, p. 68). El aspecto más importante para comprender la inflación en América Latina, sin embargo, estaría en la observación de la estructura económica de nuestros países, esto es, en la comprensión de la especificidad latinoamericana y de cada caso en particular, lo que excluía las reglas generales propagadas entonces por el FMI.

Para definir las características básicas del proceso inflacionario en América Latina y, con eso, incidir eficazmente en su contención de forma que no se obstaculizara el entonces anhelado desarrollo, según Noyola era preciso, antes de todo, discernir las causas de los desequilibrios económicos, desde las estructurales, las de carácter dinámico y las de carácter institucional. Con esta base, Noyola propone entonces un modelo de interpretación que todavía puede ser útil — aún más se comparadas con los modelos monetaristas vigentes:

"En este modelo se distinguen dos categorías fundamentales: las presiones inflacionarias básicas y los mecanismos de propagación. Las presiones inflacionarias básicas se originan comúnmente en desequilibrios de crecimiento localizados casi siempre en dos sectores: el comercio exterior y la agricultura. Los mecanismos de propagación pueden ser muy variados, pero normalmente se pueden agrupar en tres categorías: el mecanismo fiscal (en el cual hay que incluir el sistema de previsión social y el sistema cambiario), el mecanismo de crédito y el mecanismo de precios y reajuste de ingresos" (p. 69).

El fenómeno inflacionario estaría constituido por dos elementos, en que las llamadas "causas estructurales" son el cierne mismo del proceso mientras los "mecanismos de propagación” serían los diseminadores o aceleradores del impulso que se origina en otra parte. Al identificar estos dos momentos clave del proceso inflacionario, Noyola pone al revés la argumentación monetarista: ya no es el déficit público, un supuesto exceso crediticio o el alza sistemática de precios los grandes villanos de la historia. Sin duda son aspectos que constituyen el fenómeno, pero no están a la raíz del mismo. Canalizar todas las fuerzas de acción de combate a la inflación en "corregir" los mecanismos de propagación, en esa concepción, tendría, únicamente, efecto limitado y transitorio. Mientras no se reformaran la heterogénea estructura productiva y la desigual distribución del ingreso en los países latinoamericanos — vía un proceso de industrialización sustitutivo de importaciones, diría Noyola — no se lograría atenuar las presiones inflacionarias básicas. 
Para demostrar su interpretación, Noyola se vale de los ejemplos de Chile y México. No cabe aquí reproducir detalladamente su análisis, pero conviene recordar que ahí están presentes diversos elementos claves, que hasta entonces no se consideraban en el estudio de la inflación: estructura de las exportaciones, de la producción agrícola, del empleo (y desempleo), del aparato fiscal y crediticio, de la organización de los trabajadores, entre otros factores. Utilizando este cuadro analítico, en pocas líneas y de forma sucinta, Noyola logra ofrecer una interpretación del proceso inflacionario en Chile y en México de su época mucho más profunda y sólida que las recetas económicas propagadas en aquél entonces por diversos organismos financieros multilaterales y repetidas exhaustivamente en las facultades de economía de la región. Aún así, Noyola tiene claro que su aporte es todavía una propuesta, una hipótesis de trabajo, que para funcionar como herramienta de análisis concreto debe ser contrastada con la realidad y debatida ampliamente, aunque el autor ya ofrezca importantes ilaciones sobre el fenómeno:

En rigor, no se podrían derivar conclusiones para la discusión, pero yo sí quisiera plantear como base para ella tres afirmaciones: la primera es la de que si la alternativa a la inflación es el estancamiento económico o la desocupación, es preferible optar por la primera, es decir, por la inflación. La segunda es que lo grave de la inflación no es el aumento de precios en sí mismo, sino sus consecuencias en relación al ingreso y las distorsiones que trae aparejada entre la estructura productiva y la estructura de la demanda. Y la tercera es que es posible no contener pero sí mitigar las presiones inflacionarias mediante una política fiscal muy progresiva y mediante controle de precios y mediante reajustes de salarios, controles de precios y abastecimientos, y que estos recursos de política económica son una alternativa infinitamente preferible a la política monetaria, que sólo empieza a ser eficaz en el momento que estrangula el crecimiento económico (p. 78).

Obviamente, ha pasado más de medio siglo desde que Noyola defendiera al final de su conferencia esta postura frente a la inflación y, por tanto, este fenómeno ya no puede ser tratado de igual forma. Sin embargo, no deja de llamar la atención el hecho de que sus tres afirmaciones suenen actualmente como un total desvarío - para las mentes adiestradas bajo el monetarismo. Afirmar que la inflación es preferible a un contexto de recesión económica es alzado al nivel de "sacrilegio" en contra a las "buenas prácticas de gestión” macroeconómica generalizadas en América Latina en los noventa. Quizás uno de los puntos explicativos para el "escándalo" que causa tal asertiva se encuentre en el hecho de que el discurso neoliberal ha sido absorbido demasiado fuertemente y esté de tal forma entrañado en las prácticas de las autoridades monetarias de la región que, quizás, el pensamiento crítico difícilmente se entere de esa dañina y constante presencia.

\section{Algunas conclusiones: elementos Para el Debate de la Política monetaria de GOBIERNOS PROGRESISTAS}

Evidentemente, el diagnostico y las propuestas de Noyola no son inmunes al paso del tiempo y a los cambios asistidos en América Latina en los últimos cuarenta años. No se 
trata únicamente de "actualizar" para el contexto presente el mecanismo de análisis por él desarrollado. Se trata, sobre todo, de estudiar su contribución en lo que ella tiene de más valioso: la capacidad de disentir con brillantez de lo ecuánimemente aceptado y proponer alternativas pautadas en la teoría derivada de ese mismo punto de disensión.

Así, el breve ejercicio aquí realizado lanza luz y problematiza aspectos contradictorios de los gobiernos progresistas latinoamericanos. Uno de estos aspectos - y lo levantamos únicamente a título de ejemplo — es la manutención de la banca central independiente en Venezuela $^{(10)}$. Otro aspecto igualmente preocupante a considerarse es la manutención de la dolarización formal de las economías ecuatoriana ${ }^{(1)}$ y salvadoreña - y la informal que acomete Bolivia.

Por fin, apoyándonos más en las enseñanzas de la última etapa de la contribución de Noyola - la etapa comprometida con la construcción de una sociedad distinta tras un proceso revolucionario - , algunos interrogantes legítimamente surgen de la evaluación de los gobiernos progresistas: ¿Cómo un gobierno puede comandar una transformación social radical si sigue rehén de la moneda hegemónica en su propia economía? ¿Cómo se prescinde del poderoso instrumento de transformación económica, que es la política monetaria? ¿Cuáles son las limitaciones del cambio propuesto por insistir en un esquema que solidifica la perdida de la soberanía monetaria? ¿Se puede vislumbrar una trasformación social radical sin una gestión monetaria igualmente radical? ¿Se puede, al menos, ofrecer un proyecto de desarrollo distinto de aquél instaurado por el neoliberalismo en la región abdicándose de implementar medidas que revelen una acepción de moneda de otra índole? ¿Se puede inferir que, mientras los modelos de desarrollo de los gobiernos progresistas no incorporen una visión distinta de la moneda - y, consecuentemente, mecanismos alternativos de control de la inflación - y de la importancia de esa reflexión para en el proceso de financiamiento al desarrollo, no se logrará un proyecto que materialice una sólida opción al patrón de reproducción social instaurado por el neoliberalismo?

Más que asumir la difícil tarea de contestar a estas necesarias preguntas, el presente trabajo - sustentado tanto por la trayectoria biográfica como pela contribución teórica de Juan Noyola Vazquez — tuvo como finalidad y aporte, únicamente, poner nuevamente en el debate algunas cuestiones que, tras la ofensiva neoliberal, habían sido olvidadas o tomadas como secundarias, a pesar de su plena vigencia y relevancia.

\footnotetext{
(10) Aunque en el sitio web de la Banca Central venezolana (http://www.bcv.org.ve/quebcv/naturalezabcv.htm) se afirma que "el cumplimiento del principal objetivo de un banco central, es condición necesaria para darle sostenibilidad al desarrollo de un país, y en ese sentido sus actos están en correspondencia con los fines superiores del Estado", se encuentra también la postura de que "los bancos centrales han evolucionado hasta instituirse en autoridades independientes, dedicados a mantener la estabilidad de los precios y la confianza en la moneda, calificados como un bien público fundamental". Ahora bien, asociar la "estabilidad de precios y la confianza en la moneda" (y conectarlas como el único camino del desarrollo económico) es inherente a una concepción monetarista de moneda y de rol de la banca central que fueron introducidas en la región justamente por gobiernos neoliberales.

(11) "Hoy más que nunca el peligro de la desdolarización está lejano" afirmó Correa durante una entrevista en 27 de marzo de 2009 para la radio Sonido Stereo de la ciudad de Quevedo. Adelante en la misma entrevista es categórico: "Qué más puedo decir, después de todos los desmentidos, el que sigue creyendo en esa farsa de que vamos a salir de la dolarización, ya es culpa de él". En otra oportunidad vuelve a manifestarse sobre o tema: "Hoy más que nunca está lejano el colapso de la dolarización", dijo el mandatario en 16 de abril de 2009 en entrevista concedida a la Capital Televisión.
} 


\section{REFERENCIAS BIBLIOGRAFICAS}

BIELSCHOWSKY, Ricardo. Evolución de las ideas de la CEPAL. Revista de la CEPAL, n. extraordinario, 1998a.

. (coord.). Cincuenta años de pensamiento en la CEPAL. México: Fondo de Cultura Económica, v. 1, v. 2. 1998 b.

FURTADO, Celso. La economía latinoamericana. Formación histórica y problemas contemporáneos.

8. ed. corr. y aum. (primera edición en portugués de 1969). México: Siglo XXI, 1976.

MALLORQUIN, Carlos. Ideas e historia en torno al pensamiento económico latinoamericano. México: Plaza y Valdés, 1998.

MARTÍNEZ, Ramón Escamilla; MANRIQUE, Irma. Juan F. Noyola: vida, pensamiento y obra. México: Instituto Politécnico Nacional, 1991.

NOYOLA, Juan. La economía cubana en los primeros años de la revolución y otros ensayos. México: Siglo XXI, 1978.

. Desequilibrio externo e inflación. México: UNAM, 1987.

ORTEGA, Rafael; LAFFITA, Graciela; MOLINA, Ernesto. El pensamiento económico cubano, vísperas de la revolución. Economía y Desarrollo. n. 2, v. 127, jul./dic. 2000.

PINTO, Aníbal. El análisis de la inflación: “estructuralista” y “monetarista”. Un recuento. Revista de Economía Latinoamericana. Caracas, v. 1, n. 4, oct./dic. 1961.

Inflación: raíces estructurales. Ensayos de Aníbal Pinto. México: Fondo de Cultura Económica, 1973.

SUNKEL, Osvaldo. La inflación chilena: un enfoque heterodoxo. El Trimestre Económico, oct./dic. 1958a.

Un esquema general para el análisis de la inflación. El caso de Chile. Desarrollo Económico.

n. 1 , oct./dic. 1958 b. 